\title{
Respiratory hospitalizations and respiratory syncytial virus prophylaxis in special populations
}

\author{
B. Paes • I. Mitchell • A. Li • K.L. Lanctôt
}

Received: 20 September 2011 / Accepted: 7 December 2011 / Published online: 28 December 2011

(C) The Author(s) 2011. This article is published with open access at Springerlink.com

\begin{abstract}
Palivizumab utilization, compliance, and outcomes were examined in infants with preexisting medical diseases within the Canadian Registry Database (CARESS) to aid in developing guidelines for potential "at-risk" infants in the future. Infants who received $\geq 1$ dose of palivizumab during the 2006-2010 respiratory syncytial virus (RSV) seasons at 29 sites were recruited and utilization, compliance, and outcomes related to respiratory infection/illness (RI) events were collected monthly. Hazard ratios (HRs) and 95\% confidence intervals (CIs) were calculated for premature infants $\leq 35$ completed weeks gestational age (GA) who met standard approval criteria (group 1) compared to those with medical disorders (group 2) using Cox proportional hazards regression models with adjustment for potential confounding factors. Of 7,339 registry infants, 4,880 were in group 1 and 952 in group 2, which included those with Down syndrome (20.3\%), upper airway anomalies (18.7\%), pulmonary diseases $(13.3 \%)$, and cystic fibrosis (12.3\%). Group 2 were older at enrolment $(10.2 \pm 9.2$ vs. $3.5 \pm$ 3.1 months, $p<0.0005)$, had higher GA ( $35.9 \pm 6.0$ vs. 31.0 \pm 5.4 weeks, $p<0.0005$ ), and were less compliant with
\end{abstract}

\section{B. Paes}

Department of Pediatrics, McMaster University,

Hamilton, Ontario, Canada

I. Mitchell

Department of Pediatrics, University of Calgary,

Calgary, Alberta, Canada

\section{A. Li $\cdot \mathrm{K}$. Lanctôt $(\bowtie)$}

Medical Outcomes and Research in Economics (MORE ${ }^{\circledR}$ )

Research Group, Sunnybrook Health Sciences Centre,

University of Toronto,

2075 Bayview Avenue, Room FG-05,

Toronto, Ontario M4N 3M5, Canada

e-mail: krista.lanctot@sunnybrook.ca treatment intervals $(69.4 \%$ vs. $72.6 \%, p=0.048)$. A greater proportion of group 2 infants were hospitalized for RI $(9.0 \%$ vs. $4.2 \%, p<0.0005)$ and $\operatorname{RSV}(2.4 \%$ vs. $1.3 \%, p=0.003)$ (unadjusted). Being in group 2 was associated with an increased risk of RI ( $\mathrm{HR}=2.0,95 \% \mathrm{CI} 1.5-2.5, p<0.0005)$, but not RSV hospitalization (HR=1.6, 95\%CI $0.9-2.8, p=$ 0.106). In infants receiving palivizumab, those with underlying medical disorders, though not currently approved for prophylaxis, are at higher risk for RI events compared with preterm infants. However, risk of RSV hospitalizations is similar.

Keywords Respiratory syncytial virus · Palivizumab . Premature $\cdot$ Special populations

\section{Introduction}

Respiratory syncytial virus (RSV) is an important viral respiratory pathogen in children $<2$ years of age in terms of morbidity and societal costs. Infections occur seasonally, with peaks during the winter months [21]. In Canada, the RSV season begins between October and December and typically ends between March and May of the following year.

Palivizumab is a humanized monoclonal antibody [25, 48] that has proven efficacy and safety in both premature infants $\leq 32$ weeks gestation and in children with bronchopulmonary disease (BPD) [24]. It is also equally effective in infants who completed 33-35 weeks gestation and who have additional risk factors that have been utilized to target prophylaxis cost-effectively in moderate- to high-risk infants in this cohort[12, 16, 17, 24, 26, 33, 39, 41]. A large-scale randomized trial also showed a $45 \%$ RSVpositive hospitalization rate reduction in patients with 
hemodynamically significant congenital heart disease (CHD) [15]. Several studies have since demonstrated the efficacy of palivizumab in infants $<35$ weeks gestational age (GA) and those with BPD/chronic lung disease (CLD) [40]. The Palivizumab Outcomes Registry reviewed 19,548 infants who received palivizumab between 2000 and 2004 [17] and found an RSV-positive hospitalization rate of $1.3 \%$ overall. The cohort comprised $9.1 \%$ subjects with congenital airway anomalies and severe neuromuscular disorders and there was a steady decline in RSV-positive hospitalization from $2.9 \%$ in the $2000-2001$ season to $0.7 \%$ in the 2003-2004 season.

It is important to study whether a drug is being used according to predetermined risk factors and that usage complies with provincial and national recommendations [9-11]. High-risk subjects targeted for palivizumab include premature infants born $\leq 32$ weeks GA who are $\leq 6$ months of age at the start of the RSV season, children $<2$ years of age with hemodynamically significant $\mathrm{CHD}$, and children $<2$ years of age with $\mathrm{BPD} / \mathrm{CLD}$ that require oxygen or medical therapy 6 months prior to the onset of the RSV season. Moderate- to high-risk 32-35 weeks GA infants may also receive prophylaxis based on validated Canadian and European risk scoring tools [39, 41]. Palivizumab may also be prescribed for patients with significant underlying medical conditions such as congenital airway anomalies, neuromuscular disease, immunocompromise, and Down syndrome, if they are considered at high risk of serious sequelae from RSV infection $[2,11,37]$. While the cost-effectiveness of palivizumab has been studied for approved indications, the cost-effectiveness in special populations is unknown. This is an important issue as the acquisition costs for palivizumab are substantial, but must be balanced against the cost of hospitalizations and lost quality of life. However, in the absence of established guidelines for routine prophylaxis of specific medical disorders, physicians are currently shouldered with the onus of requesting palivizumab based on emerging scientific information and perceived individual risk benefit vs. harm.

The ministry of health in each Canadian province approves RSV prophylaxis for special populations of infants on a case-by-case basis adjudicated by provincial advisory groups. For example, infants with Down syndrome both with and without CHD [4-6] and infants with cystic fibrosis $[20,23,31,45]$ are considered to be at high risk for RSV infection with consequential respiratory morbidity. Many physicians are also strongly advocating for the use of RSV prophylaxis in special populations worldwide despite the restricted guidelines published by pediatric advisory bodies nationally and internationally [35].

The Canadian Registry Database (CARESS) was established in 2005 and is a Canadian database of infants who have received at least one dose of palivizumab during the RSV season across 29 sites [33]. The primary objective of this study was to compare the utilization, compliance, and health outcomes of a palivizumab-prophylaxed cohort with preexisting medical illnesses who are not currently approved for passive RSV immunization to that of prophylaxed infants $\leq 35$ weeks gestation without underlying medical disorders who routinely qualify for RSV prophylaxis according to recommended guidelines. Collection of longterm data on seasonality, risk factors, and outcomes are necessary to evaluate the impact of prophylaxis on the incidence of RSV infections, minimize healthcare resources, and identify which pediatric subgroups receive palivizumab prophylaxis [27, 36]. The latter goal is important in order to document whether current prophylaxis administration aligns with existing position statements and such data could also influence future recommendations and set the stage for research initiatives in special populations.

\section{Methods}

The CARESS study is a prospective, observational study. The current paper presents a post hoc subanalysis of the main study. Any child receiving at least one dose of palivizumab was eligible for inclusion. Children were excluded if a parent or legal guardian could not communicate in either English or French or if the child had received palivizumab as part of a clinical trial during the study period. This study was approved by the appropriate ethics committee at all sites and, therefore, has been performed in accordance with the ethical standards laid down in the Declaration of Helsinki.

\section{Data collection}

Subjects were enrolled by the treating physician and/or research nurse. Following consent, baseline data were obtained on patient demographics, prior medical history, neonatal course, and details of palivizumab administration. Infants were categorized into the following indications: prematurity ( $\leq 35$ completed weeks gestation), BPD/CLD, hemodynamically significant CHD, or other (e.g., congenital airway anomalies and neuromuscular impairments). Follow-up telephone interviews were conducted monthly until the end of the RSV season, obtaining data on palivizumab administration, changes in baseline data, and specifics of RIs.

In the event of a hospitalization, relevant hospital records were reviewed by the site's research nurse for hospitalization criteria, length of stay, days on respiratory support and/ or intubation, potential concomitant illnesses, type of diagnostic RSV test, and medical diagnosis at the time of hospital admission as reported in the discharge summary. 
The information on each patient, once assembled at each center, was then electronically logged into the registry in an anonymous fashion.

\section{Statistical analyses}

Data were analyzed using standard descriptive methods, SPSS version 19.0 (SPSS Inc., Chicago, IL, USA). Premature infants $\leq 35$ completed weeks GA without preexisting illness who met standard approval criteria [9] (group 1) were compared to those $>35$ completed weeks GA without BPD or CHD delineated by provincial guidelines, but who had underlying medical disorders (group 2). The primary endpoints were hospitalizations for both respiratory infection/ illness (RI) and RSV. An RSV-positive hospitalization was defined as any hospitalization during which it was determined that the infant had an RSV-positive infection by rapid test, polymerase chain reaction, and/or viral culture. Hazard ratios (HRs) and 95\% confidence intervals (CIs) were calculated for both RI and RSV-positive hospitalizations in premature infants $\leq 35$ completed weeks GA who met standard approval criteria (group 1) compared to those with medical disorders (group 2) using Cox proportional hazards regression models with adjustment for potential confounding factors using a backward conditional method. A subanalysis was conducted, repeating the above analysis but comparing infants in group 2 with infants prophylaxed for all other indications (prematurity, as well as BPD/CLD and CHD) $(n=6387)$, as infants with BPD/CLD and CHD could potentially resemble group 2 infants in terms of their underlying cardiorespiratory morbidities.

\section{Results}

\section{Subjects}

Subjects were enrolled between October 2006 and May 2010. A total of 7,339 infants have been recruited in 29 Canadian sites: 5 from Western Canada (British Columbia, Alberta, Manitoba, and Saskatchewan), 22 from Central Canada (Ontario, Quebec), and 2 from Eastern Canada (New Brunswick, Newfoundland, Nova Scotia, and Prince Edward Island). The distribution of infants in the registry reflects the population distribution across Canada [43]. Further details of the CARESS registry have been published elsewhere [33]. Of the 7,339 patients, 5,832 were included in the analysis, with 4,880 subjects categorized in group 1 and 952 in group 2. The remaining 1,507 infants were excluded from the analysis as they were given prophylaxis for BPD/CLD and/or CHD or were classified under multiple categories.
Demographic information and the neonatal course are shown in Table 1. Group 2 infants were heavier and older at both birth and enrolment. A greater proportion of group 2 infants was in daycare and had siblings, though group 1 patients were more likely to be multiples. Group 1 infants also had more tobacco exposure. The two groups had, on average, similar lengths of hospital stay after birth. Group 1 infants had a more complicated course, with significantly greater proportions requiring respiratory support, oxygen therapy, and documented necrotizing enterocolitis. However, Group 2 patients tended to require longer durations of both respiratory support and oxygen therapy.

Infants in Group 2 did not meet standard approval criteria delineated by provincial RSV prophylaxis guidelines $(>35$ completed weeks GA, without BPD or CHD). Patients included those with Down syndrome (193, 20.3\%), congenital airway anomalies $(178,18.7 \%)$, pulmonary disease such as lung hypoplasia, chylothorax, and mediastinal masses (127, $13.3 \%)$, cystic fibrosis $(117,12.3 \%)$, neuromuscular disorders $(78,8.2 \%)$, multiple system disorders involving chromosomal and dysmorphology syndromes (57, 6.0\%), severe CHD aged $>2$ years $(22,2.3 \%)$, immunocompromise $(17,1.8 \%)$, and others $(163,17.1 \%)$, e.g., infants with obstructive sleep apnea, severe failure to thrive, or metabolic disease.

Over the RSV seasons, there has been a steady, proportionate increase in group 2 patients, from 5.6\% (69 out of $1,224)$ in $2006-2007$, to $10.4 \%$ (175 out of 1,686$)$ in $2007-$ 2008 , to $12.2 \%$ (246 out of 2,016) in 2008-2009, and to $19.1 \%$ (462 out of 2,413) in 2009-2010. Subanalysis indicates a marked increase in Down syndrome infants $\left(\chi^{2}=\right.$ $24.277, d f=3, p<0.0005)$, as well as in the "other" category $\left(\chi^{2}=12.667, d f=3, p=0.05\right)$ (Fig. 1).

Of the 5,832 included patients, 291 patients $(5.0 \%)$ were withdrawn. There was no significant difference between groups in the proportion of patients withdrawn $(5.0 \%$ vs. $4.9 \%, p=1.00)$. The majority were lost to follow-up (51.4\%), with no significant differences between the two groups. A total of eight infants (four in each group) died over the course of the study for causes thought not directly related to palivizumab. There was one fatality in a group 2 infant that was reported as being directly associated with an RSV-related hospitalization.

\section{Utilization and compliance}

A total of 22,465 injections were administered to infants in both groups. Infants received, on average, $3.6 \pm 1.5$ injections; group 2 infants received more injections than group 1 infants $(3.8 \pm 1.7$ vs. $4.2 \pm 1.6, t=-7.895, d f=1397, p<$ $0.0005)$. Group 2 infants were more likely to receive their first injection in the first half of the season $(68.9 \%$ vs. $\left.58.4 \%, \chi^{2}=38.580, d f=1, p<0.0005\right)$. The majority 
Table 1 Demographic information and neonatal course
${ }^{\text {a }}$ Prophylaxed infants $\leq 35$ weeks gestation without underlying medical disorders who routinely qualify for RSV prophylaxis according to recommended guidelines

${ }^{\mathrm{b}}$ Prophylaxed cohort with preexisting medical illnesses who are not currently approved for passive RSV immunization

\begin{tabular}{|c|c|c|c|}
\hline & Group $1^{\mathrm{a}}, n=4,880$ & Group $2^{\mathrm{b}}, n=952$ & $p$ value \\
\hline \multicolumn{4}{|l|}{ Demographic information } \\
\hline Male $(\%)$ & $2,751(56.4)$ & $529(55.6)$ & 0.829 \\
\hline Caucasian $(\%)$ & $3,389(69.4)$ & $711(74.7)$ & 0.001 \\
\hline In daycare $(\%)$ & $65(1.3)$ & $86(9.0)$ & $<0.0005$ \\
\hline Mean GA (weeks \pm SD) & $31.0 \pm 5.4$ & $35.9 \pm 6.0$ & $<0.0005$ \\
\hline Mean birth weight ( $\mathrm{g} \pm \mathrm{SD}$ ) & $1,597 \pm 660$ & $2,751 \pm 1,708$ & $<0.0005$ \\
\hline Mean enrolment age (months \pm SD) & $3.5 \pm 3.1$ & $10.2 \pm 9.2$ & $<0.0005$ \\
\hline Mean enrolment weight $(\mathrm{g} \pm \mathrm{SD})$ & $4,095 \pm 2,335$ & $7,292 \pm 3,044$ & $<0.0005$ \\
\hline With siblings $(\%)$ & $2,877(59.0)$ & $606(63.7)$ & 0.007 \\
\hline Multiple birth (\%) & $1,738(35.6)$ & $135(14.2)$ & $<0.0005$ \\
\hline Mother smokes $(\%)$ & $697(14.3)$ & $118(12.4)$ & 0.151 \\
\hline Mother smoked during pregnancy (\%) & $660(13.5)$ & $108(11.3)$ & 0.083 \\
\hline Smoking in home $(\%)$ & $1,375(28.2)$ & $206(21.6)$ & $<0.0005$ \\
\hline$\geq 2$ smokers in home $(\%)$ & $526(10.8)$ & $97(10.2)$ & 0.646 \\
\hline$\geq 5$ people in household $(\%)$ & $1,344(27.5)$ & $214(22.5)$ & 0.001 \\
\hline \multicolumn{4}{|l|}{ Neonatal course } \\
\hline Respiratory support (\%) & $3,041(62.3)$ & $401(42.1)$ & $<0.0005$ \\
\hline Mean duration of respiratory support (days $\pm \mathrm{SD}$ ) & $17.2 \pm 24.0$ & $29.7 \pm 56.9$ & $<0.0005$ \\
\hline Oxygen therapy (\%) & $2,648(54.3)$ & $437(45.9)$ & $<0.0005$ \\
\hline Mean duration of oxygen therapy (days \pm SD) & $25.2 \pm 39.7$ & $38.7 \pm 72.0$ & $<0.0005$ \\
\hline Documented necrotizing enterocolitis (\%) & $172(3.5)$ & $20(2.1)$ & 0.022 \\
\hline Documented sepsis $(\%)$ & $704(14.4)$ & $122(12.8)$ & 0.204 \\
\hline Surgery for patent ductus arteriosus (\%) & $196(4.0)$ & $28(2.9)$ & 0.118 \\
\hline Length of neonatal hospital stay (days \pm SD) & $46.8 \pm 71.9$ & $46.9 \pm 148.5$ & 0.983 \\
\hline
\end{tabular}

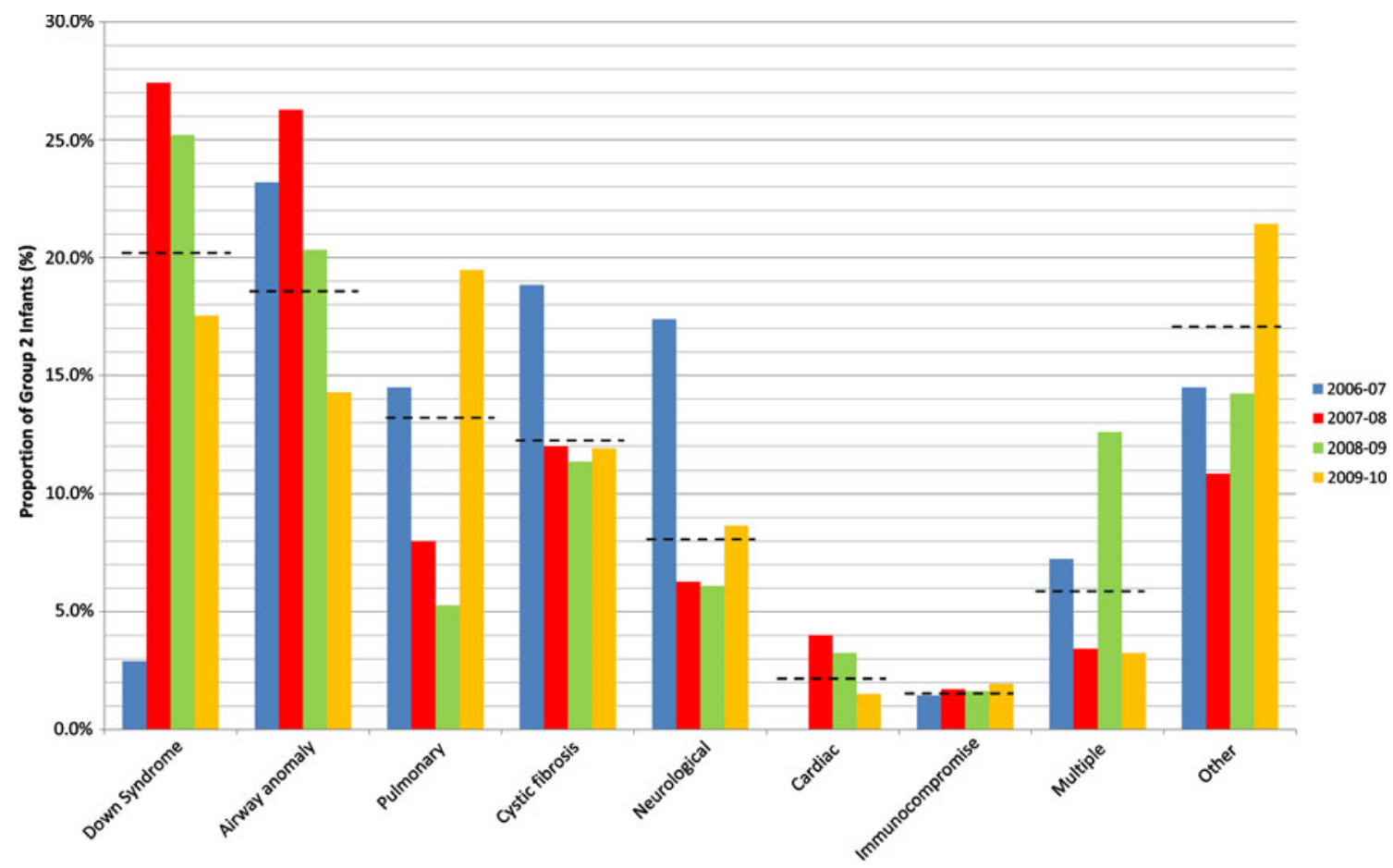

Fig. 1 Medical disorders comprising the special population group (group 2) over four RSV seasons (2006-2010). Dotted lines represent the overall percentages of each disorder subgroup 
(59.6\%) received at least four injections of palivizumab. On average, $38.8 \%$ of the infants in group 2 had received prophylaxis in a prior season.

We defined compliance in two ways: expected number of doses vs. actual number received and interdose interval. For expected number of doses, the calculation assumed monthly injections from the first dose to the end of the RSV season [28]. For number of days between injections, an interval of $30 \pm 5$ days was considered compliant. However, an interval of $20 \pm 4$ days between the first and second injections likely results in higher trough levels after the first dose, based on the pharmacokinetics of the drug and interdose palivizumab levels achieved in previous studies[24, 38]. Therefore, an interval of 16-35 days between the first and second injections was considered compliant. Infants in both groups received, on average, $92.0 \pm 29.9 \%$ of the expected number of injections. A lower proportion of group 2 infants were compliant with treatment intervals $(69.4 \%$ vs. $72.6 \%, p=0.048$ ).

As a secondary analysis, interdose interval compliance was calculated using the $30 \pm 5$ days that is recommended to providers. Under these criteria, the overall proportion of infants that were compliant with treatment drops substantially to $38.5 \%$, with group 2 infants' compliance lower than that of group 1 infants $(28.2 \%$ vs. $40.5 \%, p<0.0005)$.

\section{Hospitalizations}

In total, 290 (5.0\%) infants were hospitalized with an RI, a total of 322 times, giving an overall hospitalization rate of $5.0 \%$. The majority were admitted for respiratory distress (63.9\%). The average length of stay was $7.5 \pm 14.4$ days, with an average of $2.4 \pm 13.4$ ICU days. There was a significant difference between groups in the unadjusted proportion hospitalized: $9.0 \%$ (95\%CI 7.4-11.0) of group 2 infants were admitted for an RI vs. $4.2 \%(95 \%$ CI $3.7-4.8)$ of group $1(p<0.0005)$. Cox proportional hazard analysis confirmed that group 2 had significantly higher hazard rates $(\mathrm{HR}=2.0$, $95 \%$ CI $1.5-2.5, B=0.675, d f=1, p<0.0005$; Fig. 2a). Compliance, however, was not a significant predictor of hazard ( $p=0.805)$, nor was the interaction between group and compliance $(p=0.722)$. Subgroups within group 2 showed a wide variation in hospitalization rates (Table 2), ranging from $3.4 \%$ (cystic fibrosis) to $17.9 \%$ (neuromuscular disorders). A chi-squared analysis showed that there was a trend towards significance when comparing hospitalization rates among the subsets $\left(\chi^{2}=15.5, d f=8, p=0.051\right)$.

RSV-positive hospitalizations

Diagnostic tests for RSV were conducted 260 times on 235 infants during 322 hospitalizations. Of these, 70 tests were positive in 70 patients. Collection methods included nasal
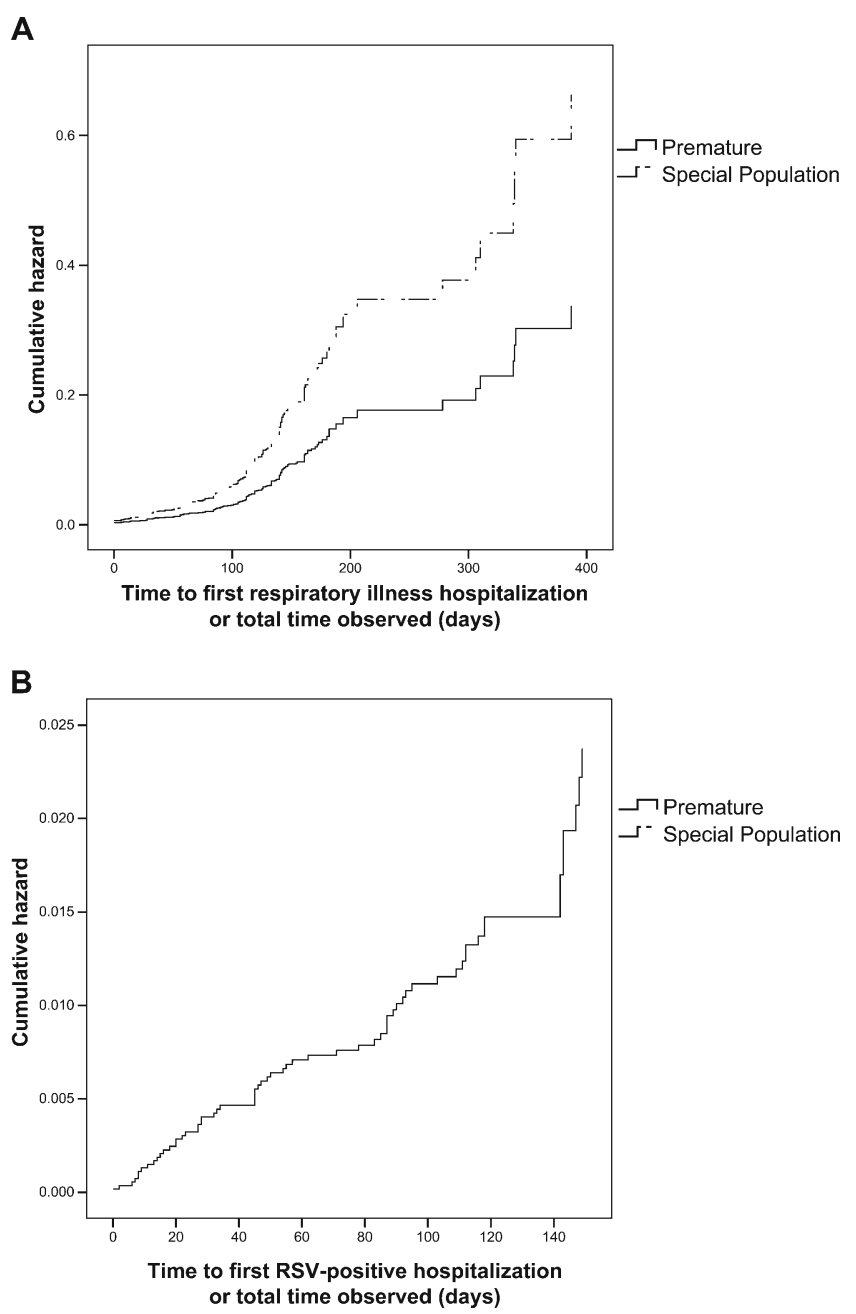

Fig. 2 Cox proportional hazards model looking at time to first hospitalization (a) and first RSV hospitalization (b), comparing hazards for group 1 (solid line) and group 2 (dotted line)

aspirate (49.4\%), nasal swab (24.8\%), and nasal wash (2.8\%), with 74 cases $(23.0 \%)$ unreported.

The overall RSV-positive hospitalization rate was $1.48 \%$. There were no significant differences between infants with and without RSV-positive hospitalization in the proportions that were fully compliant $(85.1 \%$ vs. $71.4 \%, p=0.894)$, nor in the percentage of expected injections received by each group $(92.0 \pm 29.9 \%$ vs. $88.6 \pm 22.7 \%, p=0.333$ ).

Generally, there were no significant differences between infants in groups 1 and 2 that were hospitalized with an RSV infection (Table 3 ). The only exception was with regards to respiratory support, where a greater proportion of group 2 infants required respiratory support $\left(\chi^{2}=10.961, d f=1, p=\right.$ $0.002)$ and generally required support for a longer period of time $(t=-2.122, d f=24.8, p=0.044)$. 
Table 2 RI and RSV-positive hospitalizations across group 2 subpopulations
Cohort with preexisting medical illnesses who are not currently approved for RSV prophylaxis

\begin{tabular}{lrrrrrr}
\hline & Total & Hospitalized & Tested & Positive & $\begin{array}{l}\text { RI } \\
\text { hospitalization } \\
\text { rate }\end{array}$ & $\begin{array}{l}\text { RSV } \\
\text { hospitalization } \\
\text { rate }\end{array}$ \\
\hline Cardiac & 22 & 2 & 2 & 1 & 9.1 & 4.55 \\
Pulmonary & 127 & 11 & 10 & 2 & 8.7 & 1.73 \\
Neuromuscular & 78 & 14 & 13 & 5 & 17.9 & 6.90 \\
Other & 163 & 14 & 11 & 1 & 8.6 & 0.78 \\
Multiple & 57 & 8 & 7 & 1 & 14.0 & 2.01 \\
Immunocompromised & 17 & 2 & 1 & 1 & 11.8 & 11.8 \\
Airway anomalies & 178 & 18 & 15 & 4 & 10.1 & 2.70 \\
Down syndrome & 193 & 13 & 11 & 3 & 6.7 & 1.84 \\
Cystic fibrosis & 117 & 4 & 3 & 1 & 3.4 & 1.14 \\
Total group 2 & 952 & 86 & 73 & 19 & 9.0 & 2.35 \\
\hline
\end{tabular}

A greater proportion of group 2 infants $(2.35 \%, 95 \% \mathrm{CI}$ 1.56-3.52) had an RSV-positive hospitalization compared with group 1 infants $(1.32 \%, 95 \%$ CI $1.04-1.68 ; p=0.003)$. There was no significant difference between the two groups in terms of number of days to their first RSV-positive hospitalization $(43.2 \pm 38.0$ vs. $32.5 \pm 40.6, p=0.307)$. In a Cox proportional hazards model, group 2 had a similar risk of RSV-positive hospitalization compared with group 1 $(\mathrm{HR}=1.6,95 \% \mathrm{CI} 0.96-2.86, B=0.468, d f=1, p=0.106$; Fig. $2 \mathrm{~b})$ and neither compliance $(p=0.702)$ nor the interaction of the two $(p=0.130)$ significantly affected RSVpositive hospitalization risk.

\section{Standard indications}

A subanalysis was conducted comparing infants in group 2 with infants prophylaxed for all other indications (prematurity, as well as BPD/CLD and CHD) ( $n=6,387)$. The results were similar to the original analysis. There was a significant difference between infants prophylaxed for all standard indications (prematurity, BPD/CLD, and CHD) and the special population in terms of proportion with an RI hospitalization $(5.7 \%$ vs. $9.0 \%, p<0.0005)$. Similarly, being in the special population group was associated with an increased HR for RI hospitalization (HR $=1.5,95 \% \mathrm{CI} 1.2$ $1.9, B=0.388, d f=1, p=0.001)$. A trend was found where a greater proportion of infants in the special population group had RSV hospitalizations compared to those with standard indications $(2.35 \%$ vs. $1.40 \%, p=0.062)$ (unadjusted), but HRs for RSV-positive hospitalization were again similar $(\mathrm{HR}=1.536,95 \% \mathrm{CI} 0.889-2.654, B=0.429, d f=1, p=0.124)$.

\section{Discussion}

There has been a fourfold rise over the past 4 years from $5.6 \%$ to $19.1 \%$ in infants receiving palivizumab prophylaxis for non-approved underlying medical conditions. This was primarily driven by increases in the Down syndrome category and also by those that were immunized for "other" reasons. Examples in the latter group include having a twin that qualified for prophylaxis, severe failure to thrive in association with short bowel syndromes and cholestasis, tracheostomy, severe obstructive sleep apnea, and complex metabolic disorders. The results suggest that physicians and healthcare providers are increasingly prescribing palivizumab prophylaxis

$\leq 35$ weeks gestation without underlying medical disorders who routinely qualify for RSV prophylaxis according to recommended guidelines (group $1, n=4,880$ )

Table 3 Details of RSV-positive hospitalizations in a cohort with preexisting medical illnesses who are not currently approved for passive RSV immunization (group 2, n=952) and prophylaxed infants

\begin{tabular}{llll}
\hline & Group 1 & Group 2 & $p$ value \\
\hline Mean length of stay (days \pm SD) & $7.3 \pm 6.9$ & $7.3 \pm 5.8$ & $8(40.0)$ \\
Admitted to ICU (\%) & $15(29.4)$ & $3.3 \pm 5.4$ & 0.995 \\
Mean length of stay in ICU (days \pm SD) & $1.7 \pm 3.7$ & $12(60.0)$ & 0.411 \\
Given respiratory support (\%) & $10(19.6)$ & $3.6 \pm 5.0$ & 0.241 \\
Mean length of respiratory support (days \pm SD) & $1.0 \pm 3.1$ & $5(25.0)$ & 0.002 \\
Intubated (\%) & $4(7.8)$ & $1.6 \pm 3.6$ & 0.105 \\
Mean length of intubation (days $\pm S D)$ & $0.7 \pm 2.9$ & 0.299 \\
\hline
\end{tabular}

Mean lengths of stay are calculated only for those that experienced the event 
for indications not currently recommended by position statements and provincial guidelines [2].

Differences in demographic information between the two groups showed that a greater proportion of group 2 infants were in daycare than group 1. However, this is not unexpected, as group 2 infants were, on average, older at the age of enrolment. While no significant differences were found between groups relative to expected doses received, a significantly lower percentage of group 2 infants received all their injections within the recommended time intervals. Group 2 infants were twice as likely to be hospitalized for both an RI event and RSV infection. This could be due to lower efficacy of RSV prophylaxis in this population, but this group also comprises a range of medical disorders and disease severity and our sample sizes are too small to individually elucidate the effect of immunization on RSV hospitalization in each condition. It is more likely that the severity of the preexisting medical disorder in these patients makes them generally more susceptible to RIs and perhaps RSV prophylaxis may modulate the degree of illness, but this has yet to be determined. While compliance has previously been shown to be associated with lower RSV-positive hospitalization rates [18], this was not found in the current data. However, our results concur with the Palivizumab Outcomes Registry, which also found no association between compliance and RSV-positive hospitalization [17]. Higher RSV-positive hospitalization rates have been documented in infants with other medical conditions. A retrospective cohort study of children prophylaxed in Tennessee reported that, of 3,378 hospitalizations over 4 years, $22.8 \%$ occurred in children with other medical conditions, such as Down syndrome and neuromuscular disease, while only $12.2 \%$ were attributed to prematurity [8]. Similarly, in a nationwide Japanese survey conducted from 2006 to 2008, 1,115 children aged $<4$ years who were hospitalized with RSV did not meet current criteria for prophylaxis. Among 756 infants with underlying disorders, 54.8\% had respiratory conditions, $16.5 \%$ had neuromuscular impairments, $3.6 \%$ had $\mathrm{CHD}, 1.6 \%$ were immunocompromised, $1.1 \%$ had metabolic disorders, and 5.3\% were documented with other illnesses [34]. Immunocompromised patients had a significantly worse outcome $(p<0.0001)$. There were 16 deaths and $11(68.7 \%)$ were associated with preexisting medical disorders. Other studies have found that infants with medical conditions, such as neuromuscular impairment [47], Down syndrome [6], cystic fibrosis [1, 23], and immune dysfunction [22, 29] are at higher risk of hospitalizations due to RSV infection. Preexisting disease has also been previously shown to be associated with higher morbidities and mortality rates due to RSV infection [3, 34, 44, 46].

The limitations of our study include the evaluation of patients only with specific medical conditions who were approved individually by provincial Ministries of Health and enrolled in the CARESS study. The absence of a comparative group that did not receive prophylaxis (were either not prescribed palivizumab or prescribed and did not comply with their prescription) or were hospitalized with RSV prior to prophylaxis makes it difficult to accurately gauge the effect of immunization on the reduction of RSV-related hospitalization. Hospitalized cases were not uniformly tested for RSV, and the RSV-positive hospitalization rate may be higher than $1.48 \%$. There were, however, no significant differences between the premature group and the special population group in terms of proportions of hospitalized infants tested for RSV (79\% vs. $\left.85 \%, \chi^{2}=1.179, d f=1, p=0.327\right)$. However, strengths of the study include: stringent surveillance with a well-designed data collection instrument, comprises the largest subset of reported infants with characteristic underlying medical disorders, and provides key information on risk factors and outcomes in this population over time; the absence of self-selection bias in that the spectrum of illness in the study population was diverse without a disproportionate recruitment of "healthier" infants and the entry and follow-up end points were clearly defined.

This study indicates that the "special population" infants with a range of medical disorders who were prophylaxed have a higher hazard for respiratory hospitalizations than those who routinely qualify for RSV prophylaxis, according to recommended guidelines. The difference in these rates is not related to compliance, though a lower proportion of infants in the "special population" group were compliant with treatment than premature infants. However, the special population had similar hazards for RSV-positive hospitalizations compared with those who routinely qualify for RSV prophylaxis. Historically, rates of RSV hospitalizations in those with underlying illnesses who have not received prophylaxis have been 4- to 14-fold higher than that found in this prophylaxed cohort $[1,3,6,8,22,23,29,34,44,46$, 47], though randomized controlled trials would be needed to make conclusions regarding palivizumab efficacy. While the strongest evidence supporting the use of palivizumab in infants with underlying medical illnesses is a randomized, placebo-controlled clinical trial, the requisite of an extremely large sample size in each specific medical illness makes it difficult to execute such studies. In the absence of such data, registry information can provide preliminary information on the safety and comparative effectiveness in those with who receive palivizumab as a result of medical illnesses that increase the risk of negative respiratory outcomes. Nevertheless, this study encourages healthcare providers to perform prospective trials in special populations, for example, in children with Down syndrome.

In conclusion, this present study shows that palivizumab is increasingly being used beyond the indications specified by pediatric advisory guidelines [13, 19, 30, 32, 42], and its safety in infants with medical disorders has been investigated 
in only small clinical trials [7, 14]. This reflects a better appreciation by healthcare providers of the severity of illness in these high-risk subpopulations $[20,31]$ and perhaps the perceived preventive benefit on the reduction of RSV-positive hospitalization $[15,24]$ and the concurrent potential morbidity and mortality which surpasses the likelihood of causing treatment harm. Therefore, larger prospective studies are urgently needed to demonstrate the efficacy and safety of palivizumab and its effect on hospitalizations in these groups of infants.

Acknowledgments The authors would like to thank the following investigators in the CARESS 2006-2010 seasons: Dr. Candice Bjornson (Alberta Children's Hospital), Dr. Georges Caouette (Centre Hospitalier de l'Université (CHU) Laval), Dr. Marc Lebel (CHU Sainte-Justine), Dr. Mario Eddy Dumas (CHU Sherbrooke), Dr. Charles Hui (Children's Hospital of Eastern Ontario), Dr. Ann Bayliss (Credit Valley Hospital), Dr. Bruno DiGravio (Grand River Hospital), Dr. Jean-Pierre Doray (Hôpital Charles LeMoyne), Dr. Apostolos Papageorgiou (Jewish General Hospital), Dr. Marianne Mitchell (Lakeridge Health Oshawa), Dr. Aaron Chiu (Manitoba Institute of Child Health), Dr. Bosco Paes (McMaster Children's Hospital), Dr. Roderick Canning (Moncton Hospital), Dr. Anne-Marie Canakis (Montreal Children's Hospital), Dr. Karel O’Brien (Mount Sinai Hospital), Dr. Karen Chang (Rouge Valley Hospital), Dr. Koravangattu Sankaran (Royal University Hospital), Dr. Vincent Ho (Royal Victoria Hospital), Dr. Larry Chang (Southlake Regional Health Centre), Dr. Cecil Ojah (St. John Regional Hospital), Dr. David Lee (St. Joseph's Health Care), Dr. Upton Allen (Sick Kids Hospital), Dr. Carina Majaesic (Stollery Children's Hospital), Dr. Marc Blayney (Sudbury Regional Hospital), Mr. Kiang Tang (Toronto East General Hospital), Dr. Frank Jagdis (Victoria General Hospital), Dr. Ivor Margolis (William Osler Health Centre), Dr. Godfrey Bacheyie (Windsor Regional Hospital), and Dr. Brian Simmons (Women's College Hospital).

The authors would also like to thank all the nurses, coordinators, and families for their support. The authors would like to thank Elyse Reim, Hadas Benhabib, Philip Francis, Niles Patel, and Tina Singal for their help with data collection and input.

Conflict of interest statement BP, IM, and KL have received investigator-initiated research funding from Abbott Laboratories Limited and have been compensated as advisors and/or lecturers for Abbott and MedImmune. IM has received research grants from Medimmune, SIDS Calgary, Alberta Centre for Child, Family \& Community Research, and Alberta Law Foundation. AL has received a speaker's honorarium from Abbott.

Open Access This article is distributed under the terms of the Creative Commons Attribution Noncommercial License which permits any noncommercial use, distribution, and reproduction in any medium, provided the original author(s) and source are credited.

\section{References}

1. Abman SH, Ogle JW, Butler-Simon N, Rumack CM, Accurso FJ (1988) Role of respiratory syncytial virus in early hospitalisations for respiratory distress of young infants with cystic fibrosis. J Pediatr 113:826-830

2. American Academy of Pediatrics (2009) From the American Academy of Pediatrics: Policy statements - modified recommendations for use of palivizumab for prevention of respiratory syncytial virus infections. Pediatrics 124:1694-1701

3. Arnold SR, Wang EE, Law BJ, Boucher FD, Stephens D, Robinson JL, Dobson S, Langley JM, McDonald J, MacDonald NE, Mitchell I (1999) Variable morbidity of respiratory syncytial virus infection in patients with underlying lung disease: a review of the PICNIC RSV database. Pediatric Investigators Collaborative Network on Infections in Canada. Pediatr Infect Dis J 18:866-869

4. Bloemers BL, Broers CJ, Bont L, Weijerman ME, Gemke RJ, van Furth AM (2010) Increased risk of respiratory tract infections in children with Down syndrome: the consequence of an altered immune system. Microbes Infect 12:799-808

5. Bloemers BL, van Furth AM, Weijerman ME, Gemke RJ, Broers CJ, Kimpen JL, Bont L (2010) High incidence of recurrent wheeze in children with down syndrome with and without previous respiratory syncytial virus lower respiratory tract infection. Pediatr Infect Dis J 29:39-42

6. Bloemers BL, van Furth AM, Weijerman ME, Gemke RJ, Broers CJ, van den Ende K, Kimpen JL, Strengers JL, Bont LJ (2007) Down syndrome: a novel risk factor for respiratory syncytial virus bronchiolitis - a prospective birth-cohort study. Pediatrics 120: e1076-e1081

7. Boeckh M, Berrey MM, Bowden RA, Crawford SW, Balsley J, Corey L (2001) Phase 1 evaluation of the respiratory syncytial virus-specific monoclonal antibody palivizumab in recipients of hematopoietic stem cell transplants. J Infect Dis 184:350-354

8. Boyce TG, Mellen BG, Mitchel EF Jr, Wright PF, Griffin MR (2000) Rates of hospitalisation for respiratory syncytial virus infection among children in medicaid. J Pediatr 137:865-870

9. Canadian Paediatric Society Infectious Diseases and Immunization Committee (1999) Palivizumab and respiratory syncytial virus immune globulin intravenous for the prophylaxis of respiratory syncytial virus infection in high risk infants. Paediatr Child Health 4:474-489

10. Canadian Paediatric Society Infectious Diseases and Immunization Committee, Langley JM (2003) Use of palivizumab in children without congenital heart disease. Paediatr Child Health 8:631636

11. Canadian Paediatric Society Infectious Diseases and Immunization Committee, Samson L (2009) Prevention of respiratory syncytial virus infection. Paediatr Child Health 14:521-526

12. Carbonell-Estrany X, Lazaro y de Mercado P (2009) Health economics and RSV. Paediatr Respir Rev 10(Suppl 1):12-13

13. Cohen AH, Bomar R, Cohen LE, Lesnick B, Civgi V, Kirchner K, Graham L, Montgomery G, Scott P (2001) RSV prophylaxis using palivizumab in 86 high-risk children, outside AAP red book guidelines. American Pediatrics Scoeity/Society for Pediatric Research Annual Meeting, Baltimore, pp E-PAS2001:2656

14. Cohen AH, Boron ML, Dingivan C (2005) A phase IV study of the safety of synagis (palivizumab) for prophylaxis of respiratory syncytial virus disease in children with cystic fibrosis. International Conference of the American Thoracic Society, San Diego, Abstract A53

15. Feltes TF, Cabalka AK, Meissner HC, Piazza FM, Carlin DA, Top FH Jr, Connor EM, Sondheimer HM (2003) Palivizumab prophylaxis reduces hospitalisation due to respiratory syncytial virus in young children with hemodynamically significant congenital heart disease. J Pediatr 143:532-540

16. Figueras Aloy J, Carbonell Estrany X (2010) Recommendations for the use of palivizumab in the prevention of respiratory syncytial virus infection in late preterm infants $(32(1)$ to $35(0)$ weeks of gestation). An Pediatr (Barc) 73:98 e91-98 e94

17. Frogel M, Nerwen C, Cohen A, Vanveldhuisen P, Harrington M, Boron M (2008) Prevention of hospitalisation due to respiratory syncytial virus: results from the Palivizumab Outcomes Registry. J Perinatol 28:511-517 
18. Frogel MP, Stewart DL, Hoopes M, Fernandes AW, Mahadevia PJ (2010) A systematic review of compliance with palivizumab administration for RSV immunoprophylaxis. J Manag Care Pharm 16:46-58

19. Giebels K, Marcotte JE, Podoba J, Rousseau C, Denis MH, Fauvel V, Laberge S (2008) Prophylaxis against respiratory syncytial virus in young children with cystic fibrosis. Pediatr Pulmonol 43:169-174

20. Giusti R (2009) North American synagis prophylaxis survey. Pediatr Pulmonol 44:96-98

21. Hall CB (2001) Respiratory syncytial virus and parainfluenza virus. N Engl J Med 344:1917-1928

22. Hall CB, Powell KR, MacDonald NE, Gala CL, Menegus ME, Suffin SC, Cohen HJ (1986) Respiratory syncytial viral infection in children with compromised immune function. $\mathrm{N}$ Engl $\mathrm{J}$ Med 315:77-81

23. Hiatt PW, Grace SC, Kozinetz CA, Raboudi SH, Treece DG, Taber LH, Piedra PA (1999) Effects of viral lower respiratory tract infection on lung function in infants with cystic fibrosis. Pediatrics 103:619-626

24. IMpact-RSV Study Group (1998) Palivizumab, a humanized respiratory syncytial virus monoclonal antibody, reduces hospitalisation from respiratory syncytial virus infection in high-risk infants. The IMpact-RSV Study Group. Pediatrics 102:531-537

25. Johnson S, Oliver C, Prince GA, Hemming VG, Pfarr DS, Wang SC, Dormitzer M, O'Grady J, Koenig S, Tamura JK, Woods R, Bansal G, Couchenour D, Tsao E, Hall WC, Young JF (1997) Development of a humanized monoclonal antibody (MEDI-493) with potent in vitro and in vivo activity against respiratory syncytial virus. J Infect Dis 176:1215-1224

26. Lanctot KL, Masoud ST, Paes BA, Tarride JE, Chiu A, Hui C, Francis PL, Oh PI (2008) The cost-effectiveness of palivizumab for respiratory syncytial virus prophylaxis in premature infants with a gestational age of 32-35 weeks: a Canadian-based analysis. Curr Med Res Opin 24:3223-3237

27. Law BJ, Carbonell-Estrany X, Simoes EA (2002) An update on respiratory syncytial virus epidemiology: a developed country perspective. Respir Med 96(Suppl B):S1-S7

28. Law BJ, Langley JM, Allen U, Paes B, Lee DS, Mitchell I, Sampalis J, Walti H, Robinson J, O'Brien K, Majaesic C, Caouette G, Frenette L, Le Saux N, Simmons B, Moisiuk S, Sankaran K, Ojah C, Singh AJ, Lebel MH, Bacheyie GS, Onyett $\mathrm{H}$, Michaliszyn A, Manzi P, Parison D (2004) The Pediatric Investigators Collaborative Network on Infections in Canada study of predictors of hospitalisation for respiratory syncytial virus infection for infants born at 33 through 35 completed weeks of gestation. Pediatr Infect Dis J 23:806-814

29. Ljungman P, Ward KN, Crooks BN, Parker A, Martino R, Shaw PJ, Brinch L, Brune M, De La Camara R, Dekker A, Pauksen K, Russell N, Schwarer AP, Cordonnier C (2001) Respiratory virus infections after stem cell transplantation: a prospective study from the Infectious Diseases Working Party of the European Group for Blood and Marrow Transplantation. Bone Marrow Transplant 28:479-484

30. Manzoni P, Leonessa ML, Galletto P, Gallo E, Sala U, Gomirato G, Farina D (2009) Use of palivizumab in neonates who do not meet the American Academy of Pediatrics Guidelines for respiratory syncytial virus prophylaxis. Early Hum Dev 85:S93

31. McCormick J, Southern KW (2007) A survey of palivizumab for infants with cystic fibrosis in the UK. Arch Dis Child 92:87-88

32. Michaels MG, Fonseca-Aten M, Green M, Charsha-May D, Friedman B, Seikaly M, Sanchez PJ (2009) Respiratory syncytial virus prophylaxis: a survey of pediatric solid organ transplant centers. Pediatr Transplant 13:451-456
33. Mitchell I, Paes BA, Li A, Lanctot KL (2011) CARESS: the Canadian registry of palivizumab. Pediatr Infect Dis J 30:651-655

34. Mori M, Kawashima H, Nakamura H, Nakagawa M, Kusuda S, Saji T, Tsutsumi H, Yokota S, Itoh S (2010) Nationwide survey of severe respiratory syncytial virus infection in children who do not meet indications for palivizumab in Japan. J Infect Chemother $17: 254-263$

35. Paes B, Manzoni P (2011) Special populations: do we need evidence from randomized controlled trials to support the need for respiratory syncytial virus prophylaxis? Early Hum Dev 87(Suppl 1):S55-S58

36. Paes BA (2003) Current strategies in the prevention of respiratory syncytial virus disease. Paediatr Respir Rev 4:21-27

37. Resch B, Manzoni P, Lanari M (2009) Severe respiratory syncytial virus (RSV) infection in infants with neuromuscular diseases and immune deficiency syndromes. Paediatr Respir Rev 10:148-153

38. Saez-Llorens X, Castano E, Null D, Steichen J, Sanchez PJ, Ramilo O, Top FH Jr, Connor E (1998) Safety and pharmacokinetics of an intramuscular humanized monoclonal antibody to respiratory syncytial virus in premature infants and infants with bronchopulmonary dysplasia. The MEDI-493 Study Group. Pediatr Infect Dis J 17:787-791

39. Sampalis JS, Langley J, Carbonell-Estrany X, Paes B, O'Brien K, Allen U, Mitchell I, Aloy JF, Pedraz C, Michaliszyn AF (2008) Development and validation of a risk scoring tool to predict respiratory syncytial virus hospitalisation in premature infants born at 33 through 35 completed weeks of gestation. Med Decis Making 28:471-480

40. Simoes EA (2002) Immunoprophylaxis of respiratory syncytial virus: global experience. Respir Res 3(Suppl 1):S26-S33

41. Simoes EA, Carbonell-Estrany X, Fullarton JR, Liese JG, Figueras-Aloy J, Doering G, Guzman J (2008) A predictive model for respiratory syncytial virus (RSV) hospitalisation of premature infants born at 33-35 weeks of gestational age, based on data from the Spanish FLIP Study. Respir Res 9:78

42. Speer ME, Fernandes CJ, Boron M, Groothuis JR (2008) Use of palivizumab for prevention of hospitalisation as a result of respiratory syncytial virus in infants with cystic fibrosis. Pediatr Infect Dis J 27:559-561

43. Statistics Canada (2009) Quarterly demographic estimates: July to September 2009 (Catalogue \# 91-002-X)

44. Thorburn K (2009) Pre-existing disease is associated with a significantly higher risk of death in severe respiratory syncytial virus infection. Arch Dis Child 94:99-103

45. Van Ewijk BE, Wolfs TF, Aerts PC, Van Kessel KP, Fleer A, Kimpen JL, Van der Ent CK (2007) RSV mediates Pseudomonas aeruginosa binding to cystic fibrosis and normal epithelial cells. Pediatr Res 61:398-403

46. Welliver RC Sr, Checchia PA, Bauman JH, Fernandes AW, Mahadevia PJ, Hall CB (2010) Fatality rates in published reports of RSV hospitalisations among high-risk and otherwise healthy children. Curr Med Res Opin 26:2175-2181

47. Wilkesmann A, Ammann RA, Schildgen O, Eis-Hubinger AM, Muller A, Seidenberg J, Stephan V, Rieger C, Herting E, Wygold T, Hornschuh F, Groothuis JR, Simon A (2007) Hospitalized children with respiratory syncytial virus infection and neuromuscular impairment face an increased risk of a complicated course. Pediatr Infect Dis J 26:485-491

48. Young J (2002) Development of a potent respiratory syncytial virus-specific monoclonal antibody for the prevention of serious lower respiratory tract disease in infants. Respir Med 96(Suppl B): S31-S35 